\title{
Surgical correction after Bosentan treatment in a patient with severe pulmonary hypertension
}

\author{
Ali Can Vuran \\ University of Health Sciences, Ümraniye Training and Research Hospital, İstanbul, Turkey
}

\begin{abstract}
Many patients with congenital heart disease have anomalies leading to left-to-right shunt flow between the systemic and pulmonary circulation. Most of these patients can be preserved from pulmonary hypertension and permanent damages by early non-invasive diagnostic methods and by medical and surgical treatment in appropriate timing. In a small portion of this group of patients, due to the presence of a connection leading to a very large shunt, delayed diagnosis and the presence of concomitant diseases such as Down syndrome, which is predisposing to the development of vasculopathy in the lung vessels, serious pulmonary hypertension may occur and may be obstacle surgical correction. This situation, which limits the possibility of surgical treatment, the quality of life and the life time of the patients, has been positively affected by the recent development of the drugs used in the treatment of pulmonary hypertension and made possible usage of the "treat and repair" procedure for selected cases. Our case report was a five years old girl -who was diagnosed when she was six months old but not followed up- with large artery transposition, ventricular septal defect and severe pulmonary hypertension, which was considered unsuitable for surgical treatment due to 11.5 pulmonary vascular resistance under oxygen at the time of her admission and decided to follow wit conservative treatment. After her recourse at nine years old, she treated two months vasodilator therapy than operated based on the results of control catheter angiography. The early postoperative smooth course and mid-term follow-up results of the patient support the successful implementation of the "Treat and Repair" strategy with appropriate planning in this group of patients.
\end{abstract}

Keywords: Bosentan; pediatric heart surgery; pulmonary hypertension; surgical correction.

Cite this article as: Vuran AC. Surgical correction after Bosentan treatment in a patient with severe pulmonary hypertension. Jour Umraniye Pediatr 2021;1(1):11-13. 


\section{Ağır pulmoner hipertansiyonlu hastada bosentan tedavisi sonrası cerrahi tam düzeltme}

\section{ÖZET}

Doğumsal kalp hastalığına sahip birçok hastada sistemik ve pulmoner dolaşım arasında soldan sağa şant akımına yol açan anomalilere rastlanmaktadır. Bu hastaların büyük bir kısmı invaziv olmayan tanı yöntemleri ile yaşamın erken dönemlerinde saptanıp uygun zamanda medikal ve cerrahi tedavi edilerek pulmoner hipertansiyon ve sebep olabileceği kalıcı hasarlardan korunabilmektedir. Bu grup hastaların küçük bir kısmında ise çok geniş şanta yol açan bağlantı varlığı, gecikmiş tanı alması ve akciğer damarlarında vaskülopati gelişimine yatkınlık olan Down sendromu gibi yandaş hastalıkların varlığı nedeni ile cerrahi düzeltmeye engel olabilecek seviyede pulmoner hipertansiyon oluşabilmektedir. Cerrahi tedavi imkânını, hastaların yaşam kalitesi ve süresini sınırlayan bu durum, pulmoner hipertansiyon tedavisinde kullanılan ilaçların son dönemlerdeki gelişiminden olumlu yönde etkilenmiş olup seçilmiş olgular için "tedavi et ve onar" prosedürünün kullanımına imkân vermiştir. Bu yazıda, alt aylıkken tanı almasına rağmen takip edilememiş, beş yaşındaki başvurusu esnasında oksijen altında 11.5 wood pulmoner vasküler direnç nedeni ile cerrahi tedaviye uygun olmadığı kabul edilip sonrasında konservatif tedavi ile izlenen büyük arter transpozisyonu, ventriküler septal defekt ve ciddi pulmoner hipertansiyonu olan bir kız çocuğu sunulmuştur. Dokuz yaşındaki başvurusu sonrası iki aylık vazodilatör tedavisi uygulanan ve kontrol kateter anjiyografi sonuçları ile düzeltme operasyonu yapılan hastanın ameliyat sonrası erken dönem sorunsuz seyri ve orta dönem izlem sonuçları bu grup hastalarda "Tedavi et ve Onar" stratejisinin uygun planlama ile başarılı uygulanabileceğini desteklemektedir.

Anahtar Kelimeler: Bosentan; cerrahi düzeltme; çocuk kalp cerrahisi; pulmoner hipertansiyon.

\section{GíRiş}

Doğumsal kalp hastalıklarına bağı pulmoner arteriyel hipertansiyon (PAH) sıklığı 1.6-12.5 olgu/milyon/yıl olarak bildirilmiştir. Doğumsal kalp hastalarında fonksiyonel kapasiteyi olumsuz etkileyen en önemli faktörlerden biri PAH'tır. PAH olgularının \%1'inde Eisenmenger sendromu gelişmektedir. Sağdan sola şanta yol açan $\mathrm{PAH}$, morbidite ve mortaliteyi arttirmada belirleyicidir ve beş yıllık mortalitesinin \%20'nin üzerinde olduğu belirtilmiştir $(1,2)$.

Geç tanı alan olgulardaki en önemli sorun $P A H^{\prime} ı n$ geri dönüşümsüz pulmoner yatak değişikliklerine yol açmasıdır. İlk başvurunun gecikmesine veya müdahale zamanının gecikmesine bağlı olarak önemli sayıda olgu tanı veya girişim safhasında ilerlemiş $\mathrm{PAH}^{\prime} \mathrm{a}$ sahip olmaktadır. Geçmiş dönemde bu hastalarda düzeltici cerrahi onarım tedavi seçenekleri arasında yer almazken, son yıllarda pulmoner vazodilatör tedavilerde yaşanan olumlu gelişmelerle seçilmiş hastalar için cerrahi düzeltme mümkün olabilmiştir.

\section{OLGU SUNUMU}

Sunulan olgu dokuz yaşında bir kız çocuğu idi. Kırsal bölgede ikamet etmesi nedeni ile büyük arterlerin transpozisyonu ve ventriküler septal defekt (VSD) raporu ile doğumsal kalp hastalığı tanısını gecikmiş dönemde, altı aylıkken almış, takip ve tedaviye devam etmemiştir. Beş yaşındayken dış merkeze nefes darlığı, çabuk yorulma ve ellerde morarma şikayetiyle başvurmuştur. Pulse oksimetre ile ölçülen oksijen satürasyonu değeri \%72 olarak kaydedilmiştir. Laboratuvar sonuçlarında hemoglobinin $16 \mathrm{~g} / \mathrm{dL}$ üzerinde olduğu izlenmiş ve ekokardiyografik tanı sonrası yapılan kateter anjiyografisinde Taussig bing anomalisi, çoklu VSD (outlet ve musküler), valvüler pulmoner stenoz (biküspit kapak ve 35 mmHg tepe gradyan), koroner arter anomalisi (tek kök), atriyal septal defekt ve ciddi PAH saptanmış ve cerrahi tedavi için uygun görülmemiştir. Konservatif destek tedavi ile izleminde şikayetleri artan hasta dokuz yaşındaki başvurusu esnasında New York Kalp Cemiyeti sınıflamasına göre üçüncü kategoride yer almakta idi. Almakta olduğu enalapril, asetilsalisilik asit ve diüretik tedavinin klinik durumunda düzelme sağlamaması nedeni ile bosentan ile pulmoner vazodilatör tedavi başlanmış ve haftalık kontrollü yükseltme ile iki aylık süreçte kateter anjiyografi ile tekrar değerlendirilmiştir. Iki kateter anjiyografide elde edilen veriler karşılaştırmalı olarak Tablo 1'de görülmektedir. Tedavi sonrası pulmoner vasküler direnç ve pulmoner arter basınçlarında gözlenen olumlu değişim sonrası hastanın cerrahi düzeltilmesine karar verilmiştir.

$18 \mathrm{~kg}$ ve $0.76 \mathrm{~m}^{2}$ vücut yüzey alanına sahip olan hastada standart açık kalp cerrahisi teknikleri; median sternotomi, yüksek çıkan aorta ve bikaval venöz kanülasyon, kardiyopulmoner baypas, orta derece hipotermi, aort çapraz klemp ve kan kardiyoplejik arrest kullanılarak sağ atriyotomi yolu ile otolog perikard yama ile VSD'lerin kapatılması, neoaort kapak valvulotomi ve Edward Bove tekniği ile arteriyel Switch operasyonu yapılmıştır.

\begin{tabular}{|lccc|}
\multicolumn{4}{|c}{ Tablo 1. Kateter anjiyografi verileri } \\
\hline & $\begin{array}{c}\mathbf{5} \text { yaş, } \\
\text { oksijensiz }\end{array}$ & $\begin{array}{c}\mathbf{5} \text { yaş, } \\
\text { oksijenli }\end{array}$ & $\mathbf{9}$ yaş \\
\hline Aort & $75 / 54 \mathrm{mmHg}$ & & $90 / 78 \mathrm{mmHg}$ \\
Pulmoner arter & $68 / 45 \mathrm{mmHg}$ & & $55 / 43 \mathrm{mmHg}$ \\
PVRi & $12.8 \mathrm{wood}$ & 11.50 wood & $4.8 \mathrm{wood}$ \\
SVRi & $11.2 \mathrm{wood}$ & 13.8 wood & $15.5 \mathrm{wood}$ \\
Qp/Qs & 0.58 & 0.77 & 1.5
\end{tabular}

PVRI: Pulmoner vasküler direnç indeksi; SVRi: Sistemik vasküler direnç indeksi; Qp/Qs: Pulmoner dolaşımın sistemik dolaşıma oranı. 
Erken dönem dekompresyon görevi görmesi amacıyla $4 \mathrm{~mm}$ atriyal septal açıklık bırakılmıştır.

Peroperatif verilerde kompleks cerrahi girişime bağlı olarak uzun bir kardiyopulmoner dolaşım zamanı (228 dakika) ve çapraz klemp zamanı (137 dakika) izlenmektedir. Kardiyopulmoner dolaşımdan orta derece inotrop destek altında ayrılan hastada supraventriküler taşikardi (SVT) nedeni ile iki kez defibrilasyon uygulanması harici sorun gözlenmemiştir. İnvaziv ölçümlerde 13 $\mathrm{mmHg}$ sol atriyal basınç, 45/18 mmHg pulmoner arter basıncı ve 95/60 mmHg sistemik arteriyel basınç kaydedilmiştir. Peroperatif dönemde SVT harici sorun izlenmeyen hasta sternum ve cilt kapatılarak mekanik solunum desteği ile yoğun bakım izlemine alınmıştır.

Ameliyat sonrası izleminde SVT atağı nedeni ile infüzyonu ile tedavi uygulanmış ve hemodinamik stabil seyir ile ameliyat sonrası birinci günde mekanik solunum desteğinden sorunsuz ayrılmıştır. İntraoperatif başlanan milrinon desteği haricinde inhaler ilioprost ile pulmoner basınca yönelik tedavi uygulanmıştır. Ameliyat sonrası ikinci gün dijitalizasyon uygulanan ve infüzyon tedavisi tedricen azaltılıp kapatılan hasta yedinci günde normal servis takibine alınmış ve onuncu günde taburcu edilmiştir. Servis izleminde oksijensiz satürasyon değerleri \%90-95 saptanan hastanın taburcu esnasındaki medikal tedavisinde bosentan, asetilsalisilik asit ve diüretik tedavi yer almaktadır.

Birinci ay kontrolünde New York Kalp Cemiyeti sınıflamasına göre 1-2 derecede olduğu izlenen hastanın ekokardiyografisinde hafif triküspit yetmezliği, patent foramen ovale ve sol sağ şant, biküspit neo-aortik kapakta $27 \mathrm{mmHg}$ gradyan, ejeksiyon fraksiyonu \%58 olarak saptanmıştır. Bosentan tedavisi kesilen hasta diüretik ve asetilsalisilik asit ile takip edilmiştir. Hastanın klinik olarak izlemde olduğu iki yıl boyunca kardiyak ve pulmoner morbidite izlenmemiştir.

\section{TARTIŞMA}

Şiddetli PAH sık rastlanan bir durum olmamasına rağmen ciddi morbidite ve yüksek mortalite riskine yol açması nedeni ile önemli bir sağlık sorunu olarak karşımıza çıkmaktadır. Hastalığın seviyesini gösteren basınç ve direnç verileri tam anlamıyla erken ve geç dönem sonuçlarla uyumluluk göstermese bile yaygın kabul edilen kriterlere göre pulmoner vasküler direnç imdeksi $6 \mathrm{WU} \times \mathrm{m}^{2}$ den düşük ve pulmoner vasküler direnç/sistemik vasküler direnç oranının 0.3 'ten düşük olduğu olgular biventriküler tamir için vazoreaktivite testi gerekmeksizin opere edilebilmektedir. Doğumsal kalp hastalıklarına bağı PAH'ın erken tanı ve uygun cerrahi girişim ile geri dönüşümsüz faza girmeden tedavisi birçok hastada başarılı bir şekilde sağlanmaktadır. Bu tedavinin gerçekleştirilemediği hastalarda da medikal tedavi ve bakım şartlarında sağlanan iyileşmeler sonucu morbidite gelişim oranı azaltılabilmiş ve yaşam süresinde kayda değer artış sağlanabilmiştir. Tüm bunlara rağmen şiddetli pulmoner hipertansiyonu olan hastalarda özellikle kalp yetmezliği, endokardit, ani ölüm ve vasküler trombozlar nedeni ile yüksek mortalite riski sürmektedir ve hayatta kalanların yaşam kalitesi olumsuz etkilenmektedir. Son dönemlerde pulmoner vazodilatör tedavi seçeneklerinin gelişimi, artan kullanımı ve mekanik ventilasyon tekniklerindeki gelişmelere paralel olarak; cerrahi müdahale şansını kaybettiği kararı alınan hastalarda da "Tedavi et ve Onar" stratejisi olarak tanımlanan pulmoner vazodilatör tedavinin uygulanması sonrası cerrahi tedavinin başarılı olarak uygulandığı olgu sunumları literatürde artan sayılarla yer almaktadır. Endotelin reseptör antagonistleri, fosfodiesteraz inhibitörleri ve intravenöz prostasiklin ilaçlar ve bunların kombinasyonlarının etkinliği ve faydasını gösteren veriler artarak devam etmektedir (3-5). Buradaki olguda olduğu gibi seçilmiş olgularda yakın takip ve pulmoner vazodilatör tedavi uygulaması sonrasında sonuçların dikkatli ve karşılaştırmalı olarak tekrar değerlendirilmesi sonucunda kompleks olgularda dahi erken dönem kabul edilebilir risk oranı ile anatomik tam düzeltmenin başarı ile sağlanabildiği görülmektedir. Bu gruptaki hastaların olabildiğince erken tanı almasının önemi kadar geç saptanmış hastaların uygun şartlara sahip tanı ve tedavi merkezlerine yönlendirilmesi de önem taşımaktadır. Bu şartlara sahip olan merkezlerde "Tedavi et ve Onar" stratejisi uygulanarak seçilmiş hastalarda cerrahi onarım seçeneğinin güvenli ve başarılı şekilde uygulanabildiğini ve orta dönem takip sonuçlarına dayanarak yaşam kalitesi ve süresine olumlu etki ettiğini düşünmekteyiz.

Hasta Onamı: Olgu sunumu ve beraberindeki görüntülerin yayınlanması için hastanın ailesinden yazılı bilgilendirilmiş onam alındı.

Çıkar Çatışması: Yazarlar çıkar çatışması bildirmemişlerdir.

Mali Destek: Yazarlar bu çalışma için mali destek almadıklarını beyan etmişlerdir.

Informed Consent: Written informed consent was obtained from the patient for the publication of the case report and the accompanying images.

Conflict of Interest: No conflict of interest was declared by the authors.

Financial Disclosure: The authors declared that this study has received no financial support.

\section{KAYNAKLAR}

1. Dimopoulos K, Peset A, Gatzoulis MA. Evaluating operability in adults with congenital heart disease and the role of pretreatment with targeted pulmonary arterial hypertension therapy. Int J Cardiol 2008;129:163-71.

2. Galiè N, Humbert M, Vachiery JL, Gibbs S, Lang I, Torbicki A, et al. 2015 ESC/ERS Guidelines for the diagnosis and treatment of pulmonary hypertension: The Joint Task Force for the Diagnosis and Treatment of Pulmonary Hypertension of the European Society of Cardiology (ESC) and the European Respiratory Society (ERS): Endorsed by: Association for European Paediatric and Congenital Cardiology (AEPC), International Society for Heart and Lung Transplantation (ISHLT). Eur Respir J 2015;46:903-75

3. Hu L, Tan LH, Ye J. Repair of ventricular septal defect with Eisenmenger syndrome after bosentan treatment. J Card Surg 2014;29:401-2.

4. Myers PO, Tissot C, Beghetti M. Treat-and-repair approach to Eisenmenger syndrome. J Card Surg 2014;29:836.

5. Arvind B, Relan J, Kothari SS. "Treat and repair" strategy for shunt lesions: a critical review. Pulm Circ 2020;10:2045894020917885. 